\title{
Internet-based stress management for women with preterm labour - a case-based experience report
}

\author{
Sandra Scherer • Corinne Urech • Irene Hösli • \\ Sibil Tschudin • Jens Gaab • Thomas Berger • \\ Judith Alder
}

Received: 24 March 2014 / Accepted: 30 July 2014 / Published online: 16 August 2014

(C) Springer-Verlag Wien 2014

\begin{abstract}
Pregnant women with preterm labour (PTL) in pregnancy often experience increased distress and anxieties regarding both the pregnancy and the child's health. The pathogenesis of PTL is, among other causes, related to the stress-associated activation of the maternal-foetal stress system. In spite of these psychobiological associations, only a few research studies have investigated the potential of psychological stress-reducing interventions. The following paper will present an online anxiety and stress management self-help program for pregnant women with PTL. Structure and content of the program will be illustrated by a case-based experience report. L.B., 32 years $(\mathrm{G} 3, \mathrm{P} 1)$, was recruited at gestational week 27 while hospitalized for PTL for 3 weeks. She worked independently through the program for 6 weeks and had regular written contact with a therapist. Processing the program had a positive impact on L.B.'s anxiety and stress levels, as well as on her experienced depressive symptoms and bonding to the foetus. As PTL and the risk of PTB are associated with distress, psychological stress-reducing interventions might be beneficial. This study examines the applicability of an online intervention for pregnant women with PTL. The case report illustrates how adequate low-threshold psychological support could be provided to these women.
\end{abstract}

S. Scherer $(\bowtie) \cdot$ C. Urech · I. Hösli • S. Tschudin

Women's University Hospital Basel, Basel, Switzerland

e-mail: sandra.scherer@usb.ch

J. Gaab $\cdot$ J. Alder

Department of Clinical Psychology and Psychotherapy,

Institute for Psychology, University of Basel, Basel, Switzerland

T. Berger

Department of Clinical Psychology and Psychotherapy,

Institute for Psychology, University of Bern, Bern, Switzerland
Keywords Pregnancy · Preterm labour · Online therapy · Anxiety and stress management

\section{Introduction}

Pregnancy in general is associated with joyful expectations, but it can also be associated with significant distress and anxiety, especially in the case of complications such as preterm labour (PTL) (Weidner et al. 2010; Brandon et al. 2008). As in most of the Western World, around $7.3 \%$ of the children in Switzerland are born before a gestational age of $37 \mathrm{com}$ pleted weeks (BfS 2012). The aetiology of preterm birth (PTB) is multifactorial, but at least $50 \%$ of PTBs are idiopathic and result from spontaneous preterm labour (Moutquin 2003). Besides various medical risk conditions (infections, malformations, premature rupture of membranes and others), chronic stress has been identified as a risk factor for PTL (Schneider and Spätling 2006). Studies on prenatal maternal stress indicate a relationship to prematurity. The concomitant activation of maternal stress-associated biomarkers seems to be associated with PTB (Ruiz et al. 2003; de Weerth and Buitelaar 2005; Behrman and Butler 2007). McGrath et al. (2002) found associations between an abnormal corticotropinreleasing hormone (CRH) production, observed in early pregnancy and subsequent spontaneous PTB. In a study by Stamatelou et al. (2009), women with PTL displayed sixfold higher CRH concentrations at 28 to 34 weeks of gestation than women who gave birth on time. In a review by Giurgescu (2009), the influence of maternal cortisol levels on the risk of PTB was examined, showing that higher maternal cortisol concentrations in early pregnancy correlate positively with PTB.

Beside the neuroendocrine correlates of stress, several studies also indicate an association between maternal psychological distress itself - especially anxiety and depression- 
and adverse obstetric outcomes (Alder et al. 2007; Behrman and Butler 2007; Grote et al. 2010). Various studies show that women with high scores of pregnancy-specific anxiety have an increased risk of PTB (Dole et al. 2003; Orr et al. 2007). Pregnancy-specific anxiety seems to be positively related to the blood level of CRH between the 28th and 30th week of gestation. In addition, both parameters are negatively associated with gestational age at birth (Rini et al. 1999; Mancuso et al. 2004). Furthermore, the diagnosis of PTL itself is linked to a wide range of emotional responses, which may, in turn, increase the stress response (Brandon et al. 2008; Weidner et al. 2010).

Even if psychobiological associations were identified and the influences of maternal psychological distress on PTL were demonstrated, the use of specific psychological stressreducing interventions in pregnancy has not yet been evaluated systematically.

As a field of research and a novel form of treatment, Internet-based interventions have rapidly grown in significance. Benefitting from easy accessibility and providing low-threshold treatment (Berger and Andersson 2009), Internet-based interventions are especially suited for women with PTL, who are often limited in their mobility. Internetbased psychological treatments have received more and more attention in psychotherapy research. Systematic reviews and meta-analyses indicate that Internet-based treatments can result in positive outcomes for symptoms of anxiety and depression (Andersson and Cuijpers 2009; Barak et al. 2008; Spek et al. 2007), but also for various other health conditions (Andersson et al. 2011; Cuijpers et al. 2008). Indeed, there are controlled trials suggesting that Internet-based interventions can be as effective as face-to-face psychotherapy (Wagner et al. 2014).

Based on these previous findings, an online anxiety and stress management-guided self-help program for pregnant women has been developed, being currently evaluated in a randomized-controlled trial. The following case study describes the course of an individual patient through the assessment and the intervention. Based on this case report, the feasibility and applicability of an Internet-based stress management intervention for PTL will be illustrated.

\section{Materials and methods}

The cognitive-behavioural online program is adapted from established stress and anxiety management interventions developed by Kaluza (2004). The particular items are specifically adapted for German-speaking pregnant women with medically diagnosed PTL.

The web-based self-help program is composed of six different modules that build on each other and provide strategies to reduce anxiety and stress. The program lasts 6 weeks. The participants have the opportunity to work independently and within a flexible time structure on the program elements. The modules consist of predetermined contents and information units complemented and reinforced by interactive exercises and protocols (Table 1). Within the program, participants have the opportunity to share their own experiences in a forum with other women. In addition, the participants and a therapist communicate regularly via written exchange. Apart from answering questions that may arise, the minimal contact format includes weekly feedback from the therapist. Participants also have the option to pose pregnancy-specific questions to the study team's midwife.

\section{Recruitment procedure}

Eligible women are recruited through websites for pregnant women, women's magazines and from collaborating obstetric clinics, gynaecologists and midwives. German-speaking women with medically diagnosed PTL can start with the intervention program anytime between the 18th and 32 nd week of gestation. Interested women submitted a written consent form and a written release from medical confidentiality for the monitoring medical professional. The local ethics committee approved the study protocol. After registration, the medical situation is assessed together with the monitoring physician in charge of prenatal care. High-risk patients with severe medical complications (placenta praevia, uterine and cervical anomalies, current vaginal bleeding, severe infections, premature rupture of membranes and foetal malformations) as well as women with a positive screening for psychosis, suicidal tendencies or substance abuse disorder (except nicotine) are excluded from the program. Exclusion criteria were confirmed by the monitoring medical professional and complemented with the help of the Patient Health Questionnaire (PHQ-D) (Gräfe et al. 2004). In a phone conversation with the participant, the essential exclusion was discussed and the inclusion in a more adequate support service was subsequently organized. Prior to the start of the program, the participants are informed about the program structure and additional support opportunities. Every woman in the program is monitored and accompanied throughout the program by a trained psychologist or a psychologist-to-be under supervision.

\section{Outcome measures}

The following psychometric questionnaires are employed to assess important psychological parameters, which have been shown to either have an effect on or to be affected by PTL. All questionnaires are assessed before and after the intervention.

Perceived Stress Scale (PSS) (Cohen et al. 1983): This commonly used self-assessment scale measures the extent to which certain situations are deemed stressful. The scale shows 
Table 1 Intervention program-content

\begin{tabular}{|c|c|}
\hline \multicolumn{2}{|l|}{ Psycho-education } \\
\hline Key elements & Content \\
\hline Information about stress and anxiety & $\begin{array}{l}\text { Information on stress, anxiety and how they relate to the physiology of pregnancy is } \\
\text { provided to enhance the understanding of personal reactions, emotions and symptoms. }\end{array}$ \\
\hline Individual stress model & $\begin{array}{l}\text { Development of an individual stress model, meaning existing stressors, vulnerabilities } \\
\text { and resources are identified and included in a personal stress model. }\end{array}$ \\
\hline \multicolumn{2}{|l|}{ Stabilization } \\
\hline Key elements & Content \\
\hline Activity diary & $\begin{array}{l}\text { Reflection on and restructuring of activities is carried out with the help of a daily activity } \\
\text { diary. The step-by-step patterning of the week, congruence between activities and } \\
\text { perceived mood and the planning of positive activities is introduced. }\end{array}$ \\
\hline Relaxation exercises & $\begin{array}{l}\text { The program provides guided imagination and mindfulness exercises (downloadable). } \\
\text { Personal experiences of each sequence can be documented in a protocol. }\end{array}$ \\
\hline \multicolumn{2}{|l|}{ Cognitive restructuring } \\
\hline Key elements & Content \\
\hline Individual stress protocol & $\begin{array}{l}\text { Analysis of stressful situations along with a detailed description of the situation and } \\
\text { the related feelings and thoughts. }\end{array}$ \\
\hline Coping cards & $\begin{array}{l}\text { Based on the individual stress protocol, cognitive interventions focus on the identification } \\
\text { and reappraisal of stress-associated thoughts. }\end{array}$ \\
\hline \multicolumn{2}{|l|}{ Problem solving training } \\
\hline Key elements & Content \\
\hline Problem solving protocol & $\begin{array}{l}\text { Recognition, evaluation (rating of advantages and disadvantages) and planning of } \\
\text { solutions with the help of a problem solving protocol. }\end{array}$ \\
\hline \multicolumn{2}{|l|}{ Upcoming parenthood } \\
\hline Key elements & Content \\
\hline $\begin{array}{l}\text { Information on stress triggers, baby blues and } \\
\text { postpartum depression }\end{array}$ & $\begin{array}{l}\text { Psycho-educative elements on topics such as parenthood and potential stress triggers, } \\
\text { baby blues and postpartum depression. }\end{array}$ \\
\hline Personal wishes for the time after birth & Development of attainable personal wishes for the time after birth. \\
\hline
\end{tabular}

satisfactory values with regard to reliability and validity (Cronbach's $\alpha>0.84$ ).

Pregnancy-Related Anxiety Test (PRAT) (Rini et al. 1999): The 10-item questionnaire assesses a woman's worries about her own health, the baby's health, the course of the pregnancy, the delivery and what concerns she has regarding care for her baby. The internal reliability of the PRAT is acceptable with Cronbach's $\alpha=0.78$.

Spielberger's State-Trait Anxiety Inventory (STAI) (Spielberger et al. 1983): The scale assesses both general trait anxiety and current state anxiety. The questionnaire has been validated in German (Laux et al. 1981) with a high internal consistency (Cronbach's $\alpha=0.88$ (trait) and 0.90-0.94 (state)).

Edinburgh Postnatal Depression Scale (EPDS) (Cox et al. 1987): The EPDS is widely used in perinatal mental health research. Threshold scores of $\geq 10$ (moderate probability for a depressive illness) and of $\geq 13$ (high probability for a depressive illness) were used. Originally designed to screen for postnatal depression, the scale was later validated for use during pregnancy (Murray and Cox 1990). The German version shows an acceptable internal consistency (Cronbach's $\alpha=0.81$ ) (Bergant et al. 1998).
Prenatal Bonding Questionnaire (PB) (Reading et al. 1984): The PB reviews the fulfilment with being pregnant as well as the bonding with the child and has a high reliability (Cronbach's $\alpha=0.90-0.93$ ).

Apart from psychological data, the frequency of use of the contact function, the total time in the program and the time spent in each module is recorded. After the birth, detailed data regarding the pregnancy and birth outcome are collected in cooperation with the monitoring medical professional.

\section{Case report}

L.B. is a 32-year-old female patient, diagnosed with cervical insufficiency and PTL in her third pregnancy. In 2009, she delivered spontaneously in the 39 th +1 week of gestation after an uncomplicated pregnancy. A year later, L.B. suffered an early miscarriage. Despite an IVF treatment, the current pregnancy occurred spontaneously. In early pregnancy, she had unspecified vaginal bleeding (gestational week 10). L.B. was diagnosed with a cervical shortening to $5 \mathrm{~mm}$ and the first signs of PTL at gestational week 24. The medical treatment 
included cerclage, tocolysis (bryophyllum, nifedipine, indomethacin), pulmonary maturation and the administration of antibiotics at the 24th week of gestation. L.B. was recruited in July 2012 in gestational week 27 . She became aware of the program through a midwife at the hospital. In the written consent form, she agreed that the collected data will be scientifically evaluated and published anonymously. L.B. was further informed that her data will be published in a case study.

The psychological state in the pretreatment measure showed increased stress, anxiety and depression values (Table 2).

\section{Process of treatment}

Psycho-education: In the first week, L.B. logged into the program on 3 days and worked for a total of $70 \mathrm{~min}$ through the psycho-educational information. Using a rating scale, L.B. worked on her individual stress model by assessing her experienced stressors and resources and adding her personal vulnerabilities. Her individual stress model displayed high distress ratings in the following areas: pregnancy complications, fears, worries, sadness and frustration. L.B. regarded her current life negatively. In the range of vulnerabilities, she was biased by the mentioned early abortion and the IVF treatment. L.B. had not previously suffered from a mental disorder and had never undergone psychological treatment. Her documented resources were encouraging: besides a good network of social support, she also had access to many personal resources such as tolerance, honesty, self-confidence and volition. At the start of the program, she lacked specific periods of recovery or leisure activities allowing her to regain her levels of energy.

Stabilization: In the forum, L.B. formulated her difficulties with her activity restriction well:

Now I'm lying there, waiting until the day passes and hoping to not get any contractions. I'm catching up on reading. I have read thousands of pages during entire afternoons. I also pass the time surfing in the Internet, writing emails and watching TV. Right now every day counts.

Table 2 Pretreatment and Post-treatment measures of L.B.

\begin{tabular}{lll}
\hline & Pretreatment & Post-treatment \\
\hline Perceived stress PSS & 84 & 56 \\
Pregnancy-related anxiety PRA & 2.9 & 2.3 \\
State anxiety STAI I & 53 & 39 \\
Trait anxiety STAI II & 49 & 38 \\
Depression EPDS & 14 & 9 \\
Prenatal bonding PB & 56 & 62 \\
\hline
\end{tabular}

L.B. completed the activity diary over the entire span of the program. Figure 1 shows an example of one of her first weeks on the program.

By progressively journalizing all of her activities, L.B. started to evaluate more and more moments of pleasure in everyday life.

For me it was always so nice when I was able to go onto the terrace. Blue sky, sun, fresh air ... was always very helpful.

In week 5, there were inputs such as "chocolate croissants for brunch", "watching son and husband swimming in the pool" or "finally dyed my gray hair!"

In the stabilization phase, L.B. engaged primarily in relaxation exercises. At the beginning, she reported specific difficulties in applying the exercises. She declared having trouble focusing on the instructional voice, reviving both the ideas and images and blocking out ambient noises. However, with regular practice, L.B. made rapid progress and, after a few sessions, reported better focus on the instructional voice. She achieved a significant relaxation of her breathing and managed to distract herself from negative thoughts during the exercises.

Cognitive reappraisal: Over the course of the program, L.B. wrote eight different stress protocols, thereby identifying her stress-enhancing thoughts (Fig. 2). The coping cards enabled her to independently reevaluate her stress-enhancing thoughts and offered the possibility to deal with unfavourable appraisals (Fig. 3).

Behavioural therapy: The coping cards, and the subsequent problem solving protocol, revealed that it was helpful for L.B. to apply her own strategies in the first phase of a stressful situation. Suitable soothing strategies included performing relaxation exercises or distracting herself with TV. In this phase, the specific planning of implementing those strategies played a significant role.

Upcoming parenthood: L.B. had several wishes and goals for the time after giving birth. Besides wishes for herself, many goals looked towards her future family life. Over the course of the module she adjusted to her personal goals to increase the likelihood of a successful implementation in everyday life.

I will be fit and happy after delivery $\rightarrow$ the delivery is certainly exhausting and I hope that I will recover quickly

Our son should love the baby and should not be jealous $\rightarrow$ Certainly there will be situations in which jealousy cannot be avoided. I hope I will cope with it successfully

Contact with the therapist and midwives as well as the utilization of the exchange forum: L.B. mainly used the forum 


\begin{tabular}{|c|c|c|c|c|c|c|c|}
\hline & $\begin{array}{c}\text { Monday } \\
23.07 .2012\end{array}$ & $\begin{array}{c}\text { Tuesday } \\
24.07 .2012\end{array}$ & $\begin{array}{l}\text { Wednesday } \\
25.07 .2012\end{array}$ & $\begin{array}{l}\text { Thursday } \\
26.07 .2012\end{array}$ & $\begin{array}{c}\text { Friday } \\
27.07 .2012\end{array}$ & $\begin{array}{c}\text { Saturday } \\
28.07 .2012\end{array}$ & $\begin{array}{c}\text { Sunday } \\
29.07 .2012\end{array}$ \\
\hline 6 to 8 & & & & & & & $\begin{array}{c}\text { thanks to medication } \\
\text { contractions are } \\
\text { getting weaker } \\
{[2]}\end{array}$ \\
\hline 8 to 10 & $\begin{array}{l}\text { doctor's visit, } \\
\text { discussed further } \\
\text { proceed } \\
{[6]}\end{array}$ & $\begin{array}{c}\text { reading "Bund" } \\
{[5]} \\
\end{array}$ & & & & & $\begin{array}{c}\text { sleeping } \\
{[3]} \\
\end{array}$ \\
\hline \multirow[t]{2}{*}{10 to 12} & \multirow[t]{2}{*}{ reading "Bund" } & \multirow[t]{2}{*}{$\begin{array}{l}\text { visit of son, husband } \\
\text { and lunch together }\end{array}$} & $\begin{array}{c}\text { reading "Bund" } \\
{[4]} \\
\end{array}$ & \multirow{2}{*}{\begin{tabular}{|} 
getting venflon with \\
tocolytic and \\
pulmonary \\
maturation \\
{$[0]$} \\
\end{tabular}} & \multirow[t]{2}{*}{$\begin{array}{l}\text { second pulmonary } \\
\text { maturation }\end{array}$} & & \multirow[t]{2}{*}{ visit of parents } \\
\hline & & & $\begin{array}{c}\text { visit of a friend } \\
{[6]}\end{array}$ & & & & \\
\hline 12 to 14 & & & & & & $\begin{array}{c}\text { Venflon is removed } \\
{[\mathbf{8}]}\end{array}$ & \\
\hline \multirow[t]{2}{*}{14 to 16} & \multirow[t]{2}{*}{$\begin{array}{c}\text { reading a crime } \\
\text { thriller }\end{array}$} & \multirow[t]{2}{*}{ sleeping } & \multirow[t]{2}{*}{ visit of a friend } & $\begin{array}{c}\text { visit of son and } \\
\text { parents-in-law } \\
\text { [5] }\end{array}$ & \multirow[t]{2}{*}{ reading newspaper } & & \\
\hline & & & & $\begin{array}{c}\text { visit of husband } \\
{[6]}\end{array}$ & & & \\
\hline \multirow[t]{2}{*}{16 to 18} & visit of parents & reading a book & & $\begin{array}{l}\text { reading "Gala" and } \\
\text { doing a crossword }\end{array}$ & $\begin{array}{c}\text { doctor's visit: } \\
\text { Monday or Tuesday } \\
\text { go back home }\end{array}$ & $\begin{array}{l}\text { arranging photos on } \\
\text { computer }\end{array}$ & reading / sleeping \\
\hline & {$[6]$} & {$[6]$} & & [5] & [8] & [6] & [4] \\
\hline 18 to 20 & $\begin{array}{c}\text { visit of son, } \\
\text { husband, parents-in- } \\
\text { law } \\
{[7]} \\
\end{array}$ & & & & $\begin{array}{c}\text { visit of son and } \\
\text { husband } \\
\text { [6] }\end{array}$ & $\begin{array}{c}\text { visit of son and } \\
\text { husband } \\
\text { [7] }\end{array}$ & $\begin{array}{c}\text { visit of husband } \\
\text { [7] }\end{array}$ \\
\hline \multirow[t]{2}{*}{20 to 22} & \multirow[t]{2}{*}{$\begin{array}{c}\text { reading E-mails, surf } \\
\text { the internet }\end{array}$} & \multirow[t]{2}{*}{ visit of parents } & \multirow[t]{2}{*}{ relaxation exercise } & \multirow[t]{2}{*}{ relaxation exercise } & $\begin{array}{c}\text { visit of parents } \\
\text { [6] }\end{array}$ & \multirow[t]{2}{*}{$\begin{array}{l}\text { contractions activity } \\
\text { confirmed on CTG }\end{array}$} & \multirow[t]{2}{*}{ watching movie } \\
\hline & & & & & $\begin{array}{c}\text { doing Module } 3 \\
{[7]} \\
\end{array}$ & & \\
\hline 22 to 24 & & $\begin{array}{c}\text { relaxation exercise } \\
\text { [7] } \\
\end{array}$ & & & $\begin{array}{c}\text { relaxation exercise } \\
{[6]}\end{array}$ & & \\
\hline sleep & 7 hours / 2 wake up's & 6 hours / 4 wake up's & 5 hours / 6 wake up's & 5 hours / 4 wake up's & 4 hours / 4 wake up's & 5 hours / 3 wake up's & 3 hours / 8 wake up's \\
\hline
\end{tabular}

Fig. 1 Activity diary complete with perceived $\operatorname{mood}($ scale $0-10 ; 0=$ bad mood, $10=$ good mood)

area as an exchange platform. During the program, she wrote more than ten posts and started to compare notes with other participants. L.B. added in a post:
I think it's good to 'talk' with someone who is in the same situation. And you can exchange useful tips or simply get rid of worries ...
Fig. 2 Example of a stressful situation in a stress protocol

\begin{tabular}{|c|l|l|l|}
\hline \multicolumn{5}{|c|}{ SITUATION } \\
\hline $\begin{array}{c}\text { At what time does the stressful } \\
\text { moment occur? }\end{array}$ & Where does it happen? & Who is involved? & What happens? \\
\hline in the evening of 28.7.2012 & in the hospital bed & me & $\begin{array}{c}\text { contraction activity confirmed } \\
\text { on CTG }\end{array}$ \\
\hline \multicolumn{2}{|c|}{ FEELINGS } & THOUGHT \\
\hline anxiety & $80 \%$ & Intensity 0-100\% & am I giving birth now? \\
\hline insecurity & $100 \%$ & what remains to be done? \\
\hline sadness & $80 \%$ & can I not go home? \\
\hline \multicolumn{3}{|c|}{ REACTION } \\
\hline How do I behave in the situation? & \multicolumn{1}{c|}{ How do I react physically? } \\
\hline seeking the contact with the midwife, trying to lie motionless & can not sleep, crying \\
\hline
\end{tabular}


Fig. 3 Coping card

\begin{tabular}{|c|l|}
\hline Negative thoughts & \multicolumn{1}{c|}{ Stress relieving thoughts } \\
\hline \multirow{3}{*}{ Am I giving birth now? } & I will wait and try to relax \\
\cline { 2 - 2 } & The Bryophyllum helps me to relax \\
\cline { 2 - 2 } & $\begin{array}{l}\text { It takes time until the child is actually born. One can still do lot to } \\
\text { prevent }\end{array}$ \\
\hline
\end{tabular}

Over the course of the pregnancy, L.B. became increasingly concerned about a possible caesarean section. At that time, her child had rotated into a breech position. In light of this possibility, she used contact with the midwife to inform herself of possible risks, pain management and the procedure of a potential caesarean section.

Although regular feedback and motivational posts were written by the therapist, L.B. herself gave only one direct feedback at the end of the intervention program:

Somehow I always failed to answer your messages ... sorry! Meanwhile, the 35th week of gestation is completed and I am dealing with the 'final sprint', counting every day! Retrospectively, I benefitted the most from the relaxation exercises. I repeatedly take time during the day to just close my eyes and concentrate on my breathing. The activity diary was also helpful and has shown how quickly time apparently passed. In the beginning, I did not believe I would ever make it to the end of the program ... The other modules were helpful, in terms of regarding my situation with more distance and reducing the impulse to immediately get in touch with the doctor or midwife. I had a solution up my sleeve and usually this mitigated the situation. Thanks for the help! I will stay tuned until the delivery!

\section{Outcomes}

Participating in the program had a positive impact on L.B.'s coping ability. In particular, the initially reported stress and anxiety levels were considerably reduced. Depressive symptoms quantified by the EPDS dropped after the program to a subclinical range. In addition, L.B. showed closer bonds to her unborn child and the pregnancy in post-treatment measure (Table 2).

She spent a total of $13 \mathrm{~h}$ to complete the whole program, slightly above the average processing time of $10 \mathrm{~h}$ and invested most of her time in module 2 , the relaxation exercises.

L.B. gave birth to a healthy boy (birth weight of 2,730 g) at $38+0$ weeks of gestation by a primary caesarean section due to a breech presentation. No complications were recorded during the postpartum period.

\section{Discussion and conclusion}

Previous studies on psychological interventions for women with a high risk of PTB or complications in pregnancy focused mainly on social support components and relaxation exercises. Mamelle et al. (1997) examined the effect of psychological support, based on psychoanalytic concepts, in women with PTL. The authors observed a significantly reduced rate of PTB in the treatment group when compared to the control condition. A second study in 2001 showed similar results with the rate of early PTB (before the 35th week of gestation) decreasing in the psychological support group from 25 to $5.9 \%$ (Mamelle 2001). Hobel et al. (1994) showed that the rate of PTB in women with a high risk of prematurity dropped $19 \%$ after participating in a prevention program and increased prenatal care visits. An examination by Weidner et al. (2010) of a short-term psychosomatic intervention for women with a high risk of PTB indicated that the intervention showed a significant effect on anxiety scores but not on physical symptoms and labour.

Several studies have evaluated the effects of regular relaxation exercises during pregnancy (Table 3). Overall, the two

Table 3 Relaxation exercises during pregnancy

\begin{tabular}{|c|c|c|}
\hline Authors, year & Sample & Results \\
\hline Janke (1999) & Specific subgroup of women with PTL, total sample $N=107$ & Increased gestational age and birth weight \\
\hline Urech et al. (2010) & Healthy pregnant women, total sample $N=39$ & $\begin{array}{l}\text { Positive effects of guided imagery in inducing self-reported } \\
\text { relaxation and in reduction of cardiovascular activity }\end{array}$ \\
\hline Fink et al. (2012) & $\begin{array}{l}\text { Systematic review of the literature with different samples } \\
\text { of pregnant women }\end{array}$ & $\begin{array}{l}\text { Most studies indicate positive effects in relation to the } \\
\text { maternal-foetal-neonatal well-being }\end{array}$ \\
\hline Khianman et al. (2012) & Review article with pregnant women with and without PTL & $\begin{array}{l}\text { No direct effect on PTB and PTL but some evidence of reduction } \\
\text { of stress and anxiety }\end{array}$ \\
\hline
\end{tabular}


reviews pointed out that regular applied relaxation exercises in pregnancy have a positive impact on a woman's emotional state. Whereas the results regarding the direct effects of relaxation on birth outcomes are inconsistent due to the limited research.

This case study provides an overview of a guided self-help treatment for women with preterm labour. Geared towards various levels of behaviour, the program provides its participants support in structuring their daily activities, as well as in dealing with anxiety and worry. Although causal inferences about the observed changes in psychometric scores are not warranted due to the lack of a untreated control patients (included in the current RCT, see above) the results of L.B.'s post-treatment measures show that such an intervention offers the possibility to reduce the psychological burden caused by the risk of PTB. This finding is consistent with results from previous studies (Weidner et al. 2010; Khianman et al. 2012) and demonstrates that with the chosen combination of relaxation and cognitive as well as behavioural strategies, promising effects can be achieved.

By using an online guided self-help format, the program is quick and easily accessible, providing a low-threshold support. It offers the advantages of a flexible and individual utility and easy availability even for women with limited mobility. In addition, the program can supply easily integrated elements, such as relaxation exercises.

Throughout the process, L.B. rarely contacted with the therapist. Our study so far shows that frequency of therapist contact varies widely. Thus, far much of the contact consists of describing one's current situation and mood, as well as addressing technical problems. There is generally little initiative from participants in exchanging ideas concerning the program content, indicating the program contents are self-explanatory and that the program process can be managed independently.

It is likely that as the pregnancy progresses, fears about a possible PTB continuously decrease. Certain questions remain, such as, if the program effects extend beyond natural anxiety reductions and whether the effectiveness of the program has any relation to the pregnancy outcome. Such questions need to be examined in the ongoing randomized controlled study.

\section{Ethical standards}

Women gave their written informed consent prior to their inclusion in the study. The local ethics committee approved the study protocol. In the informed consent, L.B. agreed that the collected data will be scientifically evaluated and published anonymously; she was further informed that her data will be published in a case study.
Acknowledgments We would like to thank L.B. and the other women who participated in the study, as well as the medical staff, the study midwifes and the research assistants contributing to this study. The research project is supported by the Swiss National Science Foundation. Grant number: CR13I1_135060.

Conflicts of interest The authors report no declarations of interest.

\section{References}

Alder J, Fink N, Bitzer J, Hösli I, Holzgreve W (2007) Depression and anxiety during pregnancy: a risk factor for obstetric, fetal and neonatal outcome? A critical review of the literature. J Matern Fetal Neonatal Med 20(3):189-209. doi:10.1080/ 14767050701209560

Andersson G, Cuijpers P (2009) Internet-based and other computerized psychological treatments for adult depression: a meta-analysis. Cogn Behav Ther 38(4):196-205. doi:10.1080/ 16506070903318960

Andersson G, Ljotsson B, Weise C (2011) Internet-delivered treatment to promote health. Curr opin in psychiatry 24(2):168-172. doi:10. 1097/YCO.0b013e3283438028

Barak A, Hen L, Boniel-Nissim M, Shapira N (2008) A comprehensive review and a meta-analysis of the effectiveness of Internet-based psychotherapeutic interventions. J Technol Hum Serv 26:109-160

Behrman RE, Butler AS (2007) Consequences of preterm birth In: Behrman RE, Butler AS (eds) Preterm birth: causes, consequences, and prevention. 2010/07/30 edn. National Academies Press (US), Washington (DC). doi: NBK11362 [bookaccession]

Bergant AM, Nguyen T, Heim K, Ulmer H, Dapunt O (1998) German language version and validation of the Edinburgh postnatal depression scale. Dtsch Med Wochenschr 123(3):35-40. doi:10.1055/s2007-1023895

Berger T, Andersson G (2009) Internetbasierte psychotherapien: besonderheiten und empirische evidenz [Internet-based psychotherapies: characteristics and empirical evidence]. Psychother, Psychosom und med Psychol 59:159-170

BfS (2012) Fortpflanzung, Gesundheit der Neugeborenen [Reproduction, neonatal health]. Neuchâtel, Bundesamt für Statistik. http://www. bfs.admin.ch. Accessed 20 January 2014

Brandon AR, Trivedi MH, Hynan LS, Miltenberger PD, Labat DB, Rifkin JB, Stringer CA (2008) Prenatal depression in women hospitalized for obstetric risk. J Clin Psychiatry 69(4):635-643

Cohen S, Kamarck T, Mermelstein R (1983) A global measure of perceived stress. J Health Soc Behav 24(4):385-396

Cox JL, Holden JM, Sagovsky R (1987) Detection of postnatal depression. Development of the 10-item Edinburgh postnatal depression scale. Br J Psychiatry 150:782-786

Cuijpers P, van Straten A, Andersson G (2008) Internetadministered cognitive behavior therapy for health problems: a systematic review. J Behav Med 31(2):169-177. doi:10. 1007/s10865-007-9144-1

de Weerth C, Buitelaar JK (2005) Physiological stress reactivity in human pregnancy_a review. Neurosci Biobehav Rev 29(2):295-312. doi: 10.1016/j.neubiorev.2004.10.005

Dole N, Savitz DA, Hertz-Picciotto I, Siega-Riz AM, McMahon MJ, Buekens P (2003) Maternal stress and preterm birth. Am J Epidemiol 157(1):14-24

Fink NS, Urech C, Cavelti M, Alder J (2012) Relaxation during pregnancy: what are the benefits for mother, fetus, and the newborn? A 
systematic review of the literature. J Perinat Neonatal Nurs 26(4): 296-306. doi:10.1097/JPN.0b013e31823f565b

Giurgescu C (2009) Are maternal cortisol levels related to preterm birth? J Obstet Gynecol Neonatal Nurs 38(4):377-390. doi:10.1111/j.15526909.2009.01034.x

Gräfe K, Zipfel S, Herzog W, Löwe B (2004) Screening psychischer störungen mit dem "gesundheitsfragebogen für patienten (PHQ-D)" [screening for psychiatric disorders with the patient health questionnaire (PHQ)]. Diagnostica 50(4):171-181

Grote NK, Bridge JA, Gavin AR, Melville JL, Iyengar S, Katon WJ (2010) A meta-analysis of depression during pregnancy and the risk of preterm birth, low birth weight, and intrauterine growth restriction. Arch Gen Psychiatry 67(10):1012-1024. doi:10.1001/ archgenpsychiatry.2010.111

Hobel CJ, Ross MG, Bemis RL, Bragonier JR, Nessim S, Sandhu M, Bear MB, Mori B (1994) The West Los Angeles Preterm Birth Prevention Project. I. Program impact on high-risk women. Am J Obstet Gynecol 170 (1 Pt 1):54-62. doi: S0002937894004199

Janke J (1999) The effect of relaxation therapy on preterm labor outcomes. J Obstet Gynecol Neonatal Nurs 28(3):255-263

Kaluza G (2004) Stressbewältigung [stress management]. Springer, Berlin, Heidelberg

Khianman B, Pattanittum P, Thinkhamrop J, Lumbiganon P (2012) Relaxation therapy for preventing and treating preterm labour. Cochrane Database Syst Rev 8, CD007426. doi:10.1002/ 14651858.CD007426.pub2

Laux L, Glanzmann P, Schaffner P, Spielberger C (1981) Das state-trait-angstinventar [the state-trait anxiety inventory]. Beltz, Weinheim

Mamelle N (2001) Psychological prevention of early pre-term birth: a reliable benefit. Biol Neonate 79(3-4):268-273

Mamelle N, Segueilla M, Munoz F, Berland M (1997) Prevention of preterm birth in patients with symptoms of preterm labor-the benefits of psychologic support. Am J Obstet Gynecol 177(4): 947-952

Mancuso RA, Schetter CD, Rini CM, Roesch SC, Hobel CJ (2004) Maternal prenatal anxiety and corticotropin-releasing hormone associated with timing of delivery. Psychosom Med 66(5):762-769. doi:10.1097/01.psy.0000138284.70670.d5

McGrath S, McLean M, Smith D, Bisits A, Giles W, Smith R (2002) Maternal plasma corticotropin-releasing hormone trajectories vary depending on the cause of preterm delivery. Am J Obstet Gynecol 186(2):257-260

Moutquin J-M (2003) Classification and heterogeneity of preterm birth. BJOG 110:30-33
Murray D, Cox JL (1990) Screening for depression during pregnancy with the edinburgh depression scale (EPDS). Journal of Reprod and Infant Psychol 8(2):99-107

Orr ST, Reiter JP, Blazer DG, James SA (2007) Maternal prenatal pregnancy-related anxiety and spontaneous preterm birth in Baltimore, Maryland. Psychosom Med 69(6):566-570. doi:10. 1097/PSY.0b013e3180cac25d

Reading AE, Cox DN, Sledmere CM, Campbell S (1984) Psychological changes over the course of pregnancy: a study of attitudes toward the fetus/neonate. Health Psychol 3(3):211-221

Rini CK, Dunkel-Schetter C, Wadhwa PD, Sandman CA (1999) Psychological adaptation and birth outcomes: the role of personal resources, stress, and sociocultural context in pregnancy. Health Psychol 18(4):333-345

Ruiz RJ, Fullerton J, Dudley DJ (2003) The interrelationship of maternal stress, endocrine factors and inflammation on gestational length. Obstet Gynecol Surv 58(6):415-428. doi:10.1097/01.OGX. 0000071160.26072.DE

Schneider H, Spätling L (2006) Frühgeburt: pränatale und intrapartale Aspekte [Preterm birth: prenatal and intrapartal aspects]. In: Schneider H, Husslein P, Schneider KTL (eds) Die Geburtshilfe. Springer, Berlin Heidelberg, pp 463-488

Spek V, Cuijpers P, Nyklicek I, Riper H, Keyzer J, Pop V (2007) Internetbased cognitive behaviour therapy for symptoms of depression and anxiety: a meta-analysis. Psychol Med 37(3):319-328. doi:10.1017/ s0033291706008944

Spielberger CD, Gorsuch RL, Lushene R, Vagg PR, Jacobs GA (1983) Manual for the state-trait anxiety inventory. Consulting Psychologists Press, Palo Alto

Stamatelou F, Deligeoroglou E, Farmakides G, Creatsas G (2009) Abnormal progesterone and corticotropin releasing hormone levels are associated with preterm labour. Ann Acad Med Singap 38(11): 1011-1016

Urech C, Fink NS, Hösli I, Wilhelm FH, Bitzer J, Alder J (2010) Effects of relaxation on psychobiological wellbeing during pregnancy: a randomized controlled trial. Psychoneuroendocrinology 35(9): $1348-1355$

Wagner B, Horn AB, Maercker A (2014) Internet-based versus face-toface cognitive-behavioral intervention for depression: a randomized controlled non-inferiority trial. J Affect Disord 152-154:113-121. doi:10.1016/j.jad.2013.06.032

Weidner K, Bittner A, Junge-Hoffmeister J, Zimmermann K, Siedentopf F, Richter J, Joraschky P, Gatzweiler A, Stobel-Richter Y (2010) A psychosomatic intervention in pregnant in-patient women with prenatal somatic risks. J Psychosom Obstet Gynaecol 31(3):188-198. doi:10.3109/0167482X.2010.497233 